\title{
A ATUAÇÃO DO PROFESSOR ENQUANTO A TRANSFORMAÇÃO SOCIAL RADICAL NÃO SE REALIZA
}

Iael de Souza ${ }^{\mathrm{i}}$

\section{RESUMO}

Apontamos como o professor deve orientar sua atividade educativa enquanto a transformação social radical não se efetiva, e também identificamos quais as possibilidades colocadas no limite do aparelho ideológico escolar, demonstrando que é, sim, possível ir além da teoria crítico-reprodutivista. Afinal, a educação é condicionada, mas também, enquanto parte da contradição que permeia as relações sociais e de produção capitalistas, condicionante, ainda que dentro de certos limites, já que a luta pela transformação social radical deve ser travada na e pela sociedade.

Palavras-chave: Educação. Sociedade. Consciência filosófica.

\section{THE ROLE OF THE TEACHER WHILE THE RADICAL SOCIAL TRANSFORMATION DOES NOT HAPPEN}

\begin{abstract}
We point how teachers should guide their educational activity while the radical social transformation does not happen and we also identify which the possibilities placed in the limit of the ideological school apparatus are, by demonstrating that it is possible to go beyond the critical and reproductive theory. After all, education is conditioned, but it is also conditioning, yet inside certain limits, while it takes part in the contradiction that fills the social and capitalist production relations, whereas the struggle for the social radical transformation should be done in and by society.
\end{abstract}

Keywords: Education. Society. Philosophical consciousness.

\section{Introdução}

Muitos de nós nos perguntamos, enquanto professores-educadores, como devemos atuar enquanto a transformação social radical não se realiza. Como podemos contribuir através da educação ou, mais precisamente, da ação educativa, realizada nas instituições de ensino, para fomentar a criação das condições mediativas que auxiliem na concretização processual da transformação social radical, uma vez que o aparelho ideológico escolar (ALTHUSSER, 1985) e seu ensino dual (BAUDELOT; ESTABLET, 1971), reproduzem as desigualdades sociais, a divisão técnico-social do trabalho, alimentando o desenvolvimento desigual e combinado que alicerça a produção e reprodução do capital e do sistema capitalista.

Ainda assim, sendo o capital uma contradição viva, todas as dimensões e complexos sociais também contém contradições, como é o caso do complexo social da educação e do ensino institucionalizado, e são elas que criam as brechas que, reconhecidas e trabalhadas no limite da sua possibilidade, podem produzir o seu contrário, ou seja, no caso da educação, a apropriação crítica-reflexiva do patrimônio histórico-cultural acumulado pela humanidade, servindo aos dominados para que (re)elaborem sua práxis cotidiana e seu ser e estar no mundo, problematizando-os e buscando novas formas de 
equacionar os problemas enfrentados na luta de classes, tornando seus embates e ações verdadeiramente mais eficazes.

Cabe-nos, nesse artigo, referenciados no materialismo histórico-dialético, esboçar, em linhas gerais, como pode ser a atuação do professor-educador dentro das instituições de ensino ainda controladas pela ideologia da classe dominante - garantindo sua reprodução e pelo aparelho jurídico-político do Estado capitalista através das políticas públicas educacionais, a fim de que sua ação educativa possa frutificar, fortalecendo e criando as condições mediativas que contribuam para a construção do processo de transformação social radical.

\section{Contradições do complexo social da educação}

A educação, numa sociedade de classes, é uma educação de classes, ou seja, é apropriada, sistematizada, elaborada pela classe dominante, tornada política pública estatal - através do aparelho de Estado escolar -, atendendo os interesses e necessidades dessa classe que no embate de relações de força e poder (luta de classes), consegue ocupar os espaços, cargos, órgãos, funções, instituições e aparelhos que irão assegurar a criação dos meios e recursos para realizar, de forma legal, legítima e aceita socialmente, desde que revestida pela res-pública, o condicionamento e controle do social.

Dizer que a educação é "de classes" significa que carrega em si as contradições que permeiam e perpassam a sociabilidade capitalista, e que da mesma forma que ela pode ser condicionada também tem a virtualidade de ser condicionante, pois devido sua natureza essencial, que

consiste em propiciar ao indivíduo a apropriação de conhecimentos, habilidades, valores, comportamentos, etc. que se constituem em patrimônio acumulado e decantado ao longo da história da humanidade, contribuindo, assim, para que o indivíduo se construa como membro do gênero humano e se torne apto a reagir face ao novo de um modo que contribua para a reprodução do ser social, que se apresenta sempre sob uma determinada forma particular, (TONET, s/d, p. 09)

pode possibilitar que também a classe trabalhadora e seus filhos, ao se apropriarem desses conteúdos histórico-sociais, humanos - logo, não são, em si mesmos, propriedade nem de uma ou outra classe, mas sim construção de modos de ser, pensar, fazer, viver, sentir, interagir deixados e registrados, de alguma forma no mundo e para ele, de várias gerações de homens -, o reelaborem e resistematizem, ressignificando-o, construindo a síntese das múltiplas determinações que determinam o real, realizando a análise concreta das situações concretas vividas pelos homens no decorrer da processualidade dos momentos históricosociais de curta, média e longa duração vividos por eles, superando a própria perspectiva de classe e recolocando a perspectiva de humanização e hominização do ser social como critério parametrador dessa reelaboração.

Lembramos, assim, que a educação tem caráter mediativo e age de modo indireto, e não de ação/intervenção imediata e direta, pois trata-se do árduo trabalho processual de elaboração da práxis humana, da sua compreensão e não mero entendimento, tendo a potencialidade de provocar uma metanóia (mudança radical de vida e mentalidade) naqueles que são e sentem-se incomodados, provocados e provados pelos questionamentos e reflexões levantados pelas problematizações em relação à vida humano-social e das condições e circunstâncias que viabilizam ou obstaculizam o desenvolvimento do ser social e de seu processo de humanização verdadeiramente humanizadora. 
É por isso que à educação não cabe fazer a transformação social radical, não é ela o sujeito revolucionário, porém, pode contribuir, mediativamente, auxiliando aqueles que podem tornar-se esse sujeito, garantindo a apropriação e elaboração do patrimônio histórico-cultural acumulado pela humanidade de maneira retotalizadora, refazendo a totalidade social propositalmente desfeita pela visão de mundo fragmentadora do mundo moderno, repondo as mediações no lugar das representações, tecendo as conexões causais não visíveis entre as múltiplas dimensões que compõem a objetividade do real, permitindo e capacitando o ser social a retomar, socialmente, o controle sobre a direção de sua vida, utilizando, para isso, dos aparatos organizativos-mediativos de classe que possam fortalecer sua luta e torna-la, concretamente, eficaz.

Por último, destacamos um outro aspecto, muito enfatizado por Saviani (2008, 2004), que é a possibilidade, através do trabalho desenvolvido pelo professor, então consciente de sua condição de classe e tendo feito sua opção de classe e de mundo, de auxiliar os estudantes a superarem o senso comum e construírem a consciência filosófica. Como lembra Florestan, "a mudança requer luta e luta social entre classes", e numa sociedade de classes onde a educação é uma educação de classes, "um professor deve aprender em termos de luta de classes, mesmo que não seja marxista" (FERNANDES, 1986, p. 26).

Eis uma das características da educação, seu objeto é ao mesmo tempo sujeito, de modo que não se trata de uma relação apenas entre sujeito (professor) e objeto (aluno), mas entre sujeito e objeto que é também sujeito, dado que o ato educativo corresponde "a ação sobre uma consciência visando induzi-la a agir de determinada forma" (TONET, 2005, p. 218) e não de outra. De modo que o educador pode contribuir para frear ou acelerar a mudança porque questiona os fundamentos objetivos, histórico-sociais da práxis humana e dos valores correspondentes edificados a partir das relações sociais e de produção construídos pelos homens.

Por mais que a escola, enquanto instituição social, portanto, aparelho de Estado, reforce a ideologia dominante por ser aquele controlado pela classe dominante, ainda assim existem, no limite, algumas brechas, que são as virtualidades possíveis, ainda que limitadas, mas que podem e devem ser aproveitadas e trabalhadas para fortalecer e criar as condições para a construção da contra-hegemonia e luta por hegemonia da classe trabalhadora e dos seus filhos, o que só se viabiliza pela apropriação, por essa classe, do patrimônio histórico-cultural acumulado pela humanidade, mas criticamente reelaborado pela depuração da lógica dialética, que torna os conteúdos concretos, dinâmicos, processuais, porque analisados a partir dos problemas criados, colocados e enfrentados pelos homens na organização da produção e reprodução de suas condições materiais e espirituais de existência.

Porém, é lícito ressaltar, que as brechas só poderão ser alargadas se essa luta for para além das instituições escolares e de ensino, pois a educação escolar, enquanto um dos complexos sociais que compõe a totalidade dos complexos que formam a sociabilidade capitalista, só poderá ser transformada com a transformação social radical do próprio metabolismo societal. Como bem elucida Paulino José Orso (2013, p. 57 e 58),

a educação se transforma ou é transformada à medida em que também se transforma a sociedade, em que a luta se acirra. Novas relações de produção exigem novas relações sociais. Estas suscitam novas representações ideais, novas teorias, novos conceitos, novas ideias, condição para novas ações e novas práticas, para mudanças que possam ir além das do tipo estímulo resposta. Dessa forma, impõe-se mais do que nunca, conhecer cada vez melhor a sociedade, conhecer como ela se movimenta, como se transforma, para poder intervir nela nos momentos adequados. A verdadeira aprendizagem se dá na luta concreta, na 
percepção de que a sociedade de classes e a sociedade capitalista é inviável ao ser humano; na destruição das promessas e ilusões burguesas. Isso ocorre com as transformações sociais, que vão provocando novas relações e que, por sua vez, vão minando o sistema e desencadeando novas formas de se organizar e se viver socialmente.

Isso demonstra que a educação escolar, numa sociedade de classes, tem limites bem definidos, mas de maneira alguma, em momento algum, pode ser negada e negligenciada a importância imprescindível do acesso e apropriação do conhecimento científico, do patrimônio histórico-cultural acumulado pela humanidade, que reelaborado críticadialeticamente, repondo a historicidade de seus conteúdos, ou seja, as questões políticas, econômicas, culturais e as relações de poder e força que permeiam as ações, os fatos e acontecimentos que marcam a história humana, podem contribuir para a passagem do senso comum à consciência filosófica da classe trabalhadora e dos seus filhos, como defende Saviani, isso porque o próprio senso comum representa as ideias da classe dominante tornadas hegemônicas e aceitas, internalizadas e reproduzidas, consensualmente, pelos diferentes segmentos da classe trabalhadora que integram a sociedade. É assim que a

\begin{abstract}
concepção dominante (hegemônica) atua sobre a mentalidade popular articulando-a em torno dos interesses dominantes e impedindo ao mesmo tempo a expressão elaborada dos interesses populares, o que concorre para inviabilizar a organização das camadas subalternas enquanto classe. O senso comum é, pois, contraditório, dado que se constitui num amálgama integrado por elementos superficialmente explícitos caracterizados por conceitos herdados da tradição ou veiculados pela concepção hegemônica e acolhidos sem crítica. (...) E numa formação social como a nossa, marcada pelo antagonismo de classes, as relações entre senso comum e filosofia se travam na forma de luta - a luta hegemônica. Luta hegemônica significa precisamente: processo de desarticulaçãorearticulação, isto é, trata-se de desarticular dos interesses dominantes aqueles elementos que estão articulados em torno deles, mas não são inerentes à ideologia dominante e rearticulá-los em torno dos interesses populares, dandolhes a consistência, a coesão e a coerência de uma concepção de mundo elaborada, vale dizer, de uma filosofia. (SAVIANI, 2004, p. 3)
\end{abstract}

Vejamos, então, o que podem os profissionais da educação, os professores, após o delineamento dessas contradições e das possibilidades que entreabrem, ainda que limitadas, mas essenciais de serem trabalhadas para fortalecer a criação das condições para a construção da hegemonia da classe trabalhadora e sua luta contra-hegemônica ao capital e seu metabolismo social, tornando, assim, os embates travados nas lutas de classe mais promissores e eficazes ao propósito da superação da sociedade de classes, dado que terão um conhecimento mais adequado e aproximado da organização e funcionamento da realidade, desfazendo e superando as ilusões criadas e mantidas pelo capital e seu séquito, que lhe aprisiona a mente e a capacidade de refletir e enxergar sua verdadeira condição e construir sua identidade de classe.

\title{
III. Possibilidades de atuação do professor dentro do limite da sociedade de classes e do ensino escolar institucionalizado
}

A partir das considerações feitas anteriormente, aqueles profissionais da educação que querem ser o diferencial e fazer a diferença construindo, a partir do seu trabalho, as condições que contribuirão para fortalecer a perspectiva do trabalho contra a do capital e sua hegemonia, necessitam, num primeiro momento, se reconhecerem enquanto parte da classe trabalhadora e como trabalhador, dado que 
se não fosse professor, como um trabalhador que precisa vender sua força de trabalho para poder sobreviver, possivelmente estaria realizando um outro tipo de trabalho qualquer e vendendo sua força como padeiro, marceneiro, agricultor, confeiteiro, vendedor, pedreiro, coveiro, escriturário, motorista, etc. - estaria educando e sendo educado em outro local (isto porque são as relações sociais e de produção que educam e exigem um certo tipo de educação escolar que as reproduza e mantenha). (...) Muitas vezes, pelo fato de o professor trabalhar com as ideias, tem a impressão de que não é trabalhador, de que não pertence à mesma classe dos demais. Daí a importância de se reconhecer como trabalhador, como membro da mesma classe, com a 'missão' de, por intermédio do trabalho que realiza, contribuir para a superação de sua própria condição social. (ORSO, 2013, p. 61. Os parênteses são nossos.)

Trata-se, portanto, de reconhecer o lugar ocupado na estrutura produtiva e na divisão técnica social do trabalho enquanto vendedor de força de trabalho, portanto, dependente do trabalho assalariado, uma das bases de reprodução das desigualdades sociais que auxilia na cisão entre trabalho manual/trabalho intelectual. Portanto, necessita tomar conhecimento de sua condição de classe e fazer sua opção de classe a fim de que, através do seu trabalho, possa, no limite possível da estrutura institucional escolar capitalista, realizar atividades de caráter transformador, o que significa dizer indagar, questionar, provocar, desacomodar, desatrofiar e instar os estudantes à reflexão e à crítica social da organização e funcionamento da realidade, denunciando, desmistificando e desfazendo as ilusões em torno das relações sociais e de produção, evidenciando as contradições postas pelo desenvolvimento das forças produtivas que colocam em xeque o trabalho assalariado, a propriedade privada dos meios de produção, a manutenção das desigualdades sociais, enfim, o próprio cerne do metabolismo sistêmico do capital.

Parafraseando Paulino José Orso (2013, p. 62),

como profissionais da educação realizam um tipo de trabalho de certa forma privilegiado que, ao mesmo tempo, permite que os educandos tenham acesso ao saber científico historicamente acumulado e fazer a crítica radical do conhecimento e da própria sociedade que o produz. Dependendo da forma como for realizado, o trabalho pode revelar a própria condição existencial dos trabalhadores em educação e também dos demais trabalhadores, possibilitando identificar-se como pertencentes a uma classe, à classe trabalhadora. O reconhecimento dos trabalhadores em geral e dos da educação como classe e o reconhecimentos das condições a que esta classe está submetida, exige que, por meio do trabalho que realizam, contribuam para a superação de sua condição.

Ainda que essa contribuição tenha limites, dado que o máximo possível dentro da estrutura escolar e demais instituições de ensino ao longo do processo de escolarização é a passagem do senso comum à consciência filosófica e a formação pelo sujeito coletivo singular - os professores - por afinidades de valores, de ideal objetivo de homem e de mundo a se buscar e concretizar (paideia, no sentido grego), de grupos de estudo, pesquisa e trabalho que venham a aprofundar as reflexões em torno das questões histórico-sociais que desafiam e se colocam como urgentes e necessárias de serem compreendidas e respondidas para a conquista e realização da emancipação humana de toda a humanidade, onde esses grupos atuam como instrumentos mediativos-organizativos capazes de construir atividades (simpósios, seminários; participações em movimentos sociais e organização de cursos de formação em conjunto com esses movimentos; participação nos congressos que discutem e definem os rumos para a educação, etc.) e ações conjuntas com os demais movimentos sociais e órgãos da classe trabalhadora, visando a articulação de forças do 
conjunto social para as ações nas esferas produtivas que atinjam direta e imediatamente as atividades econômicas essenciais à reprodução social, produzindo movimentos de massa, mas com direcionamento e clareza dos meios que deverão ser usados para qualificar e atingir o fim por excelência, que é a emancipação humana, a superação da sociedade de classes, do Estado, da propriedade privada e do capital como forma de relação social. Como bem nos alertou Lênin, existem certas condições essenciais para a eclosão de uma "situação revolucionária"ii e dentre elas uma que é fundante e fundamental para a superação e transcendência positiva do atual estado de coisas, que é a "capacidade, no que respeita à classe revolucionária, de conduzir ações revolucionárias de massa suficientemente vigorosas para quebrar completamente (ou parcialmente) o antigo governo, que não 'cairá' jamais, mesmo em época de crise, sem 'ser derrubado"'. (LÊNIN, 1979, p. 28.)

Para isso, é necessário que a classe trabalhadora, e os profissionais da educação que atuam como seus intelectuais orgânicos, tenha se apropriado e (re)elaborado o conhecimento histórico-cultural acumulado e sistematizado pela humanidade, (re)sistematizando-o, pois a conquista da hegemonia por parte da classe trabalhadora pressupõe a conquista de determinados elementos e conhecimentos que também lhe pertencem, como: consciência política, social, econômica, além de coerência e concepção de mundo elaborada. No século XXI, com o aperfeiçoamento, difusão e mundialização da mass media, dos veículos de informação e comunicação de massa, uma outra luta se coloca como vital para a classe trabalhadora no seu confronto com o capital, somando-se a luta política. Trata-se da luta ideológica, algo percebido e sinalizado por Gramsci, que dizia que a maior das batalhas a ser travada pela classe trabalhadora seria a batalha pelas consciências e para isso, obviamente, ela deve se desenvolver e preparar culturalmente, sistematizando, refletindo, elaborando e tomando consciência das contradições e mediações que consubstanciam a práxis humana, as relações sociais e de produção na estrutura social capitalista.

\begin{abstract}
Quando esta compreensão se generalizar, quando a classe trabalhadora compreender isto, quando sua consciência for tal que não mais aceite sua condição de explorado e de classe, ela própria se transformará na força material que deporá as estruturas que a produzem e construirá as condições para humanização do homem. Cabe ao professor, por meio do trabalho que realiza, portanto, ajudar a preparar os alunos para uma nova sociedade; a ajudar ao aluno transitar do estado de consciência alienada para a superação de seu estado de classe; servir de ponte entre a realidade atual e a que se quer construir. (ORSO, 2013, p. 62)
\end{abstract}

A primeira coisa que os professores devem ter claro é a natureza essencial da educação aqui mencionada, de modo que não aceitem, lutem e denunciem aos demais as tentativas de atribuir funções à educação, à escola e aos professores que não são deles, mas de responsabilidade das políticas sociais que deveriam ser desenvolvidas pelo Estado, das quais este procura se desresponsabilizar repassando a responsabilidade para a dita sociedade civil organizada e para os próprios indivíduos sociais, ficando, assim, mais fácil identificar os culpados pelos insucessos e fracassos, responsabilizando exclusivamente os indivíduos e rotulando-os como incompetentes, incapazes, improdutivos, ineficientes, mal preparados, etc., desfocando da essência do problema que é o modo como estão organizadas as relações sociais e de produção capitalistas que sustentam e repõem o metabolismo sistêmico do capital.

Essa consciência por parte dos professores e a denúncia da lógica que perpassa os discursos, as ideias, os valores que sustentam a práxis humana na sociabilidade capitalista 
podem fazer com que suas aulas, as discussões que constroem com os alunos, as atividades que propõem, a forma como organizam e sistematizam o conhecimento histórico-cultural acumulado ganhem concretude, dinamismo e vida, interligando as situações, problemas e circunstâncias atuais vividos por nós, no presente, com aquelas vividas por outras gerações de homens, em outro tempo e lugar, demonstrando o que nos une enquanto gênero e enquanto classe, construindo nossa identidade e perspectiva de classe e consciência de “classe em si". Ilustrativa a fala de Nosella (2004, p. 53. O itálico é nosso)

\begin{abstract}
A muitos professores e colegas que me perguntam como dar aula enquanto a sociedade e a escola não mudarem, eu próprio comento esse texto de Gramsci ( $A$ Universidade Popular): primeiramente, digo-lhes, repercorram as etapas pelas quais os homens passaram ao tentar resolver seus problemas frente à natureza e à convivência social: toda disciplina nada mais é que uma série de problemas resolvidos pelos homens numa certa época e região da terra, de uma certa forma e em certas condições. Contem essa História aos alunos e façam com que eles a revivam dramaticamente, recriando assim a problemática e as soluções. Avaliem finalmente se de fato aqueles problemas (de geometria, de matemática, de física, de biologia, de linguística, etc., etc.) foram resolvidos apenas para poucos ou para muitos ou para todos os homens,
\end{abstract}

como também a fala de Gramsci (GRAMSCI apud NOSELLA, 2004, p. 173):

\begin{abstract}
enquanto a escolar for administrada por esse Estado representante dos segmentos sociais mais retrógrados, não há saída a não ser pelo professor individualmente em nível de seu 'trabalho vivente', ou seja, enquanto está consciente da contraposição cultural entre o universo escolar e o universo social e, por esta consciência, dá suas aulas em conformidade com a cultura superior representada pelos alunos (filhos dos trabalhadores).
\end{abstract}

Portanto, enquanto a educação estiver sobre controle do Estado capitalista e da classe capitalista e a escola e o ensino aos seus serviços, cabe a nós professores que atuamos procurando ser o diferencial e fazer a diferença, nos organizarmos e mobilizarmos coletivamente, não só denunciando e garantindo a apropriação, sistematização e elaboração crítica-reflexiva do patrimônio histórico-cultural acumulado pela humanidade para os filhos da classe trabalhadora, mas também e acima de tudo, contextualizar, historicizando, as ações e relações humanas a fim de que se apropriem e retotalizem a totalidade social propositalmente fragmentada e esvaziada de significado, de modo que possam construir as reflexões teóricas da práxis humana, justificando e plenificando suas vidas de sentido, construindo um projeto político-social com alma social e podendo intervir na conjuntura social quando os momentos de agravamento das condições de vida e trabalho impuserem e exigirem ações de enfrentamento imediato, que poderão, pelo conhecimento apropriado e (re)elaborado, ter desdobramentos qualitativamente diferenciados devido a clareza de como direcionar essas lutas a médio e longo prazo a fim de se alcançar o objetivo maior, que é a superação e transcendência positiva do capital.

$\mathrm{Na}$ verdade, as possibilidades da educação e da instituição escolar atuarem numa perspectiva de caráter transformadorii radical dentro dos limites impostos pela estrutura social capitalista depende da organização, mobilização e articulação do sujeito coletivo singular, isto é, dos professores, dado que são eles os condutores do processo ensinoaprendizagem, ao menos enquanto perdurar a divisão técnica-social do trabalho. O que significa que é necessário um trabalho coletivo, a construção de um projeto político-socialpedagógico por parte de um grupo de professores em conjunto com a comunidade escolar (atividades de agitação e propaganda, promovendo a organização e mobilização do coletivo, envolvendo-o a partir da identificação com tal projeto) e com os demais sujeitos 
sociais envolvidos com a construção de uma nova sociedade e um novo homem, que ao atuarem e irem ganhando legitimidade e reconhecimento por parte dos alunos e da comunidade, obriga e arrasta os demais professores, tanto os que estão em cima do muro como os opositores, a se posicionarem, colocando a nu o que antes obliteravam ou através das dissimulações conseguiam ocultar: sua perspectiva de classe e de mundo, evidenciando contra quem teremos que lutar, tornando mais racional e eficaz os meios que utilizaremos para alcançar nosso fim, meios que estarão de acordo, servirão e qualificarão esses fins, é lícito frisar.

Afinal, como nos lembra Tonet, as escolhas são fundadas em valores, sejam elas conscientes ou inconscientes e que o fim último que deve guiar o educador em suas ações educativas é, "obviamente, o valor por excelência" (TONET, 2005, p. 230). Contudo, ressalva que "não se trata de quaisquer valores, mas de valores histórica e socialmente fundados, ou seja, valores que tendo a sua base no processo real apontam para uma forma superior de sociabilidade" (TONET, 2005, p. 231). De modo que "não há receituário do que seja a atividade educativa emancipadora, (...) não está pré-estabelecido o que seja uma atividade educativa emancipadora nas suas expressões cotidianas. Tem-se, hoje, apenas parâmetros gerais. De modo que é preciso criar" (TONET, 2005, p. 231).

Porém, essa criação deve se parametrar na clareza da natureza essencial da atividade educativa, como já alertamos, na compreensão entre as relações contraditórias e dialéticas entre sociedade e educação e de que, quem educa, na verdade, é a sociedade através da práxis social e das lutas empreendidas entre as classes sociais na defesa de seus interesses e necessidades, no caso da classe trabalhadora, em defesa de suas condições de vida e trabalho, sendo altamente pedagógicas, ou seja, formadoras e educativas, desvelando aos homens as condições e circunstâncias de sua real condição socioeconômica-cultural e como os demais complexos sociais, como a educação, são condicionados pelas relações sociais e de produção, pelo desenvolvimento das forças produtivas e das contradições gestadas no interior daquelas relações de trabalho, de propriedade e de produção. Como enfatiza Marx nas Teses sobre Feuerbach (s/d, p. 208 e 209),

A teoria materialista de que os homens são produto das circunstâncias e da educação e de que, portanto, homens modificados são produto de circunstâncias diferentes e de educação modificada, esquece que as circunstâncias são modificadas precisamente pelos homens e que o próprio educador precisa ser educado. (...) A coincidência da modificação das circunstâncias e da atividade humana só pode ser apreendida e racionalmente entendida como prática transformadora.

Logo, como explica Paulino José Orso (2013, p. 57),

Marx reforça a tese de que, quem de fato educa o homem é a sociedade, tanto pelas pessoas que a fazem quanto pelas condições em que vivem. A educação corresponde ao nível de desenvolvimento das forças produtivas e das relações de produção de cada sociedade, em cada época. Assim a educação se transforma ou é transformada à medida em que também se transforma a sociedade, em que a luta se acirra. Novas relações de produção exigem novas relações sociais.

Essa é também a constatação realizada por Ivo Tonet (2005, p. 236 e 237), pois

O avanço no cumprimento da tarefa mais essencial da educação que, como vimos, é a apropriação daquelas objetivações que constituem o patrimônio comum da humanidade, não depende só e nem principalmente da atividade educativa, mas do progresso na luta, realizada pelo conjunto das classes 
subalternas, para contrapor-se à hegemonia do capital. Ou seja, muitas das condições para a realização da atividade educativa são externas ao campo da própria educação e só podem ser conquistadas com uma luta mais ampla, no entanto a concretização desta articulação é, hoje, uma tarefa extremamente difícil e complexa. (...) A realização desta tarefa essencial é sempre o momento determinante da atividade educativa. Outros momentos - atividades sindicais, lutas econômicas, políticas, etc. - são imprescindíveis e, em certas circunstâncias, poderão até assumir o papel de momento predominante. É preciso ter bem claro, porém, que de modo algum se pode inverter a relação entre esses dois momentos, sob pena de eliminar o caráter emancipador da atividade educativa.

Cabe, então, ao professor-educador-pesquisador-intelectual, pela função assumida enquanto trabalhador que se especializou na arte de ensinar-aprender dentro da divisão técnica social do trabalho na sociedade capitalista, como defende e demonstra Giroux (1997), auxiliar a perspectiva do trabalho e os trabalhadores na captura, aproximação e reflexão da processualidade, objetividade e historicidade do real, já que encontram sérios entraves para avançar nesse árduo e penoso trabalho devido o lugar que ocupam na produção social. Também necessita realizar seu trabalho da melhor maneira possível perante a limitação das condições dadas, organizando-se e mobilizando-se para lutar pelas melhorias em suas condições de trabalho e de salários, garantindo, assim, o tempo de estudo, reflexão e pesquisa indubitavelmente necessários e mesmo pressuposto de sua contribuição para a construção dos valores, ideias, ações, comportamentos, habilidades, etc. contra-hegemônicos, superando, por incorporação, a lógica formal pela lógica dialética $^{\mathrm{iv}}$, para que na construção conjunta de ações a serem desenvolvidas com os demais professores que também se posicionem enquanto classe, lutem e contribuam para a superação da realidade de classes.

Os professores que querem ser um diferencial e fazer a diferença, necessitam ter domínio e clareza sobre o funcionamento da lógica formal e da lógica dialética para que, de fato, compreendam porque essa última supera a primeira por incorporação e é a condição para superar a ênfase nas representações individuais, retomando e recolocando no centro da reflexão o que realmente importa: as mediações. Conforme Saviani (2004, p. 4 e $5)$,

a lógica dialética não é outra coisa senão o processo de construção do concreto de pensamento (ela é uma lógica concreta) ao passo que a lógica formal é o processo de construção da forma de pensamento (ela é, assim, uma lógica abstrata). Por aí, pode-se compreender o que significa dizer que a lógica dialética supera por inclusão/incorporação a lógica formal (incorporação, isto quer dizer que a lógica formal já não é tal e sim parte integrante da lógica dialética). Com efeito, o acesso ao concreto não se dá sem a mediação do abstrato (mediação da análise, como escrevi em outro lugar ou o 'detour' de que fala Kosik). Assim, aquilo que é chamado de lógica formal ganha um significado novo e deixa de ser a lógica para se converter num momento da lógica dialética. (...) A lógica dialética não tem por objetivo as leis que governam o pensamento enquanto pensamento. Seu objetivo é a expressão, no pensamento, das leis que governam o real. A lógica dialética se caracteriza, pois, pela construção de categorias saturadas de concreto. Pode, pois, ser denominada a lógica dos conteúdos, por oposição à lógica formal que é, como o nome indica, a lógica das formas. 
Portanto, a lógica dialética, o materialismo histórico-dialético de Marx, desvela, assim, a verdade objetiva do real, objetividade condicionada historicamente, evidenciando, por consequência, a condicionalidade histórica dos limites de aproximação dos nossos conhecimentos em relação à verdade que, mesmo tendo caráter aproximativo, "não conduz a uma postura cética e relativista, mas ratifica a historicidade constitutiva de todo ser existente: o mundo natural, o ser social e suas objetivações". (DELLA FONTE, Sandra Soares, 2011, p. 30) É o domínio desse conhecimento e seu exercício pelos professores no decorrer de seu trabalho em sala de aula, e demais espaços sociais extra-escolares, extrainstitucionais que sejam convidados a participar contribuindo com a reflexão, elaboração e sistematização da práxis social, reorientando, assim, as formas de luta para que se tornem mais eficazes e permitam a construção da hegemonia da classe trabalhadora, que permitirá a elevação da consciência do nível do senso comum ao da consciência filosófica.

É por isso que Saviani $(2004$, p. 6) diz que

A passagem do senso comum à consciência filosófica é condição necessária para situar a educação numa perspectiva revolucionária. Com efeito, é esta a única maneira de convertê-la em instrumento que possibilite aos membros das camadas populares a passagem da condição de 'classe em si' para a condição de "classe para si”. Ora, sem a formação da consciência de classe não existe organização e sem organização não é possível a transformação revolucionária da sociedade.

Por sua vez, Newton Duarte esclarece essa afirmação de Saviani, a fim de evitar mal entendidos e tergiversações, dizendo que

\begin{abstract}
Saviani não afirma que a educação, por si só, produzirá a passagem da consciência de classe em-si à consciência de classe para-si. O que ele afirma é que a única forma da educação escolar contribuir para essa passagem é trabalhando na direção da elevação da consciência dos alunos do nível do senso comum ao da consciência filosófica. Se, entretanto, a educação escolar mantiver o aluno no nível do senso comum, será impossível a realização na escola das 'atividades educativas emancipadoras' propostas por Tonet (2007, p. 35), como também será pouco provável que crianças, adolescentes e jovens possam encontrar 'alimento intelectual, moral e artístico noutros lugares', nas palavras de Mészáros (2005, p. 54). (DUARTE, 2012, p. 112)
\end{abstract}

É com base nessa compreensão das relações contraditórias que permeiam a sociabilidade do capital, sua estrutura produtiva-social e o complexo da educação, reconhecendo o lugar que ocupam nessa mesma estrutura produtiva a partir da divisão técnica-social do trabalho, reconhecendo-se enquanto classe e identificando-se enquanto pertencentes a uma determinada classe, a classe trabalhadora, independente de serem ou não marxistas, como assevera Florestan (1986), que os professores, dominando a lógica dialética e atuando através das atividades educativas para provocar, desacomodar, desestabilizar, incomodar as mentes e consciências dos indivíduos sociais, principalmente nas instituições de ensino público onde se encontram os filhos da classe trabalhadora (agora também marcando presença massiva no ensino superior com a criação do REUNE Reestruturação e Expansão do Ensino Superior -, SISU - Sistema de Seleção Unificada - e PROUNI - Programa Universidade Para Todos), organizando-se enquanto sujeito coletivo individual com os demais professores que apresentam concepção de mundo e de homem aproximada e se reconhecem enquanto parte da classe trabalhadora, poderão desenvolver atividades educativas de caráter transformador em conjunto com os demais setores sociais que lutam em prol da construção das condições para a superação de todas as formas de exploração e opressão do homem pelo homem. 
Concluímos, portanto, dizendo que esses professores devem ter claro o limite de suas ações dentro do aparelho institucional educativo, tendo consciência que as brechas são possibilitadas pelas contradições originadas nas relações de força e poder medidos entre as classes sociais nas lutas que travam diuturnamente nas relações sociais e de produção capitalistas reproduzidas nos diversos setores produtivos-econômicos que garantem a reprodução social, podendo fazer avançar ou refrear o caráter transformador de suas atividades educativas. Daí a importância de que a luta não se restrinja à escola e à educação e que o aluno, enquanto ainda preso ao senso comum, ainda está preso ao empírico, é, portanto, um "aluno empírico" e não um "aluno concreto", como elucida Saviani (2012, p. 79 e 80), porque ainda não conseguiu superar as ilusões produzidas e cultivadas pelo capital e inculcadas por seus aparatos e aparelhos ideológicos, reproduzindo e acreditando como seus os valores, ideias, comportamentos, atitudes, etc. da classe dominante. Como demonstrou tão bem Paulo Freire em sua obra Pedagogia do Oprimido, o oprimido se transforma no opressor, vive, pensa, se relaciona com os outros e com o mundo conforme a ideologia dominante. Por isso não é possível partir do interesse do aluno, porque o interesse do aluno empírico não é o mesmo do aluno concreto e este último só poderá se produzir e formar através da lógica dialética, potencializando suas ações e mobilizações no social e através do social, a partir do momento que se reconhece enquanto membro da classe trabalhadora e se identifica com sua condição de classe e se engaja na luta de classes.

\section{Referências}

ALTHUSSER, Louis. Aparelhos Ideológicos de Estado - Nota sobre os Aparelhos Ideológicos de Estado. Rio de Janeiro: Graal, 1985.

BAUDELOT, C. \& ESTABLET, R. L'École Capitaliste em France. Paris: François Maspero, 1971.

DELLA FONTE, Sandra Soares. Fundamentos teóricos da pedagogia histórico-crítica. In: MARSIGLIA, Ana Carolina Galvão (Org.). Pedagogia histórico-crítica: 30 anos. Campinas, SP: Autores Associados, 2011. (Coleção memória da educação)

DUARTE, Newton (et. al.). A Pedagogia Histórico-Crítica e o Marxismo - equívocos de (mais) uma crítica à obra de Dermeval Saviani. In: SAVIANI, Demerval; DUARTE, Newton. (Orgs.) Pedagogia Histórico-Crítica e luta de classes na educação escolar. Campinas, SP: Autores Associados, 2012. (Coleção polêmicas do nosso tempo)

FERNANDES, Florestan. "A formação política e o trabalho do professor". CATANI, Denice Bárbara. (Et. all.) (Orgs) Universidade, escola e formação de professores. São Paulo: Brasiliense, 1986.

GIROUX, Henry A. Os professores como intelectuais: rumo a uma pedagogia crítica da aprendizagem. Trad. Daniel Bueno. Porto Alegre: Artmed, 1997.

LENIN, Vladimir I. A falência da II Internacional. Trad. Armando Boito Júnior e Maria Luiza Gonçalves. $1^{a}$ ed. São Paulo: Kairós Livraria e Editora Ltda, 1979. (Série Materialismo Histórico)

MARX, Karl; ENGELS, Friedrich. Obras Escolhidas. v. 3. Rio de Janeiro: Editorial Vitória Ltda, s/d.

NOSELLA, Paolo. A escola de Gramsci. 3. ed. rev. e atual. São Paulo: Cortez, 2004. 
ORSO, Paulino José. A educação na sociedade de classes: possibilidades e limites. In: ORSO, Paulino José; GONÇALVES, Sebastião Rodrigues; MATTOS, Valci Maria. (Orgs) Educação e luta de classes. 2 ed. São Paulo: Expressão Popular, 2013.

SAVIANI, Dermeval. Marxismo, Educação e Pedagogia. In: SAVIANI, Dermeval; DUARTE, Newton. (Orgs.) Pedagogia Histórico-Crítica e luta de classes na educação escolar. Campinas, SP: Autores Associados, 2012. (Coleção polêmicas do nosso tempo)

SAVIANI, Dermeval. Educação: do senso comum à consciência filosófica. 15. ed, Campinas, SP: Autores Associados, 2004. (Coleção Educação Contemporânea)

TONET, Ivo. Educação, Cidadania e Emancipação Humana. Ijuí: Ed. Unijuí, 2005. (Coleção fronteiras da educação)

TONET, Ivo. Educar para a cidadania ou para a liberdade? Maceió, s/d. Disponível em: http://www.ivotonet.xpg.com.br/

\section{Notas}

${ }^{\text {i }}$ UFPI (Universidade Federal do Piauí), campus de Picos

ii impossibilidade para as classes dominantes manterem sua dominação de forma inalterada; crise da 'cúpula', crise da política da classe dominante, o que cria uma fissura através da qual o descontentamento e a indignação das classes oprimidas abrem caminho. Para que a revolução estoure não basta, normalmente, que 'a base não queira mais' viver como outrora, mas é necessário ainda que 'a cúpula não o possa mais'; 2) agravamento, além do comum, da miséria e da angústia das classes oprimidas; 3) desenvolvimento acentuado, em virtude das razões indicadas acima, da atividade das massas, que se deixam, nos períodos 'pacíficos', saquear tranquilamente, mas que, em períodos agitados, são empurradas tanto pela crise no seu conjunto como pela própria 'cúpula', para uma ação histórica independente. Sem essas alterações objetivas, independentes não somente da vontade desses ou daqueles grupos e partidos, mas também dessas ou daquelas classes, a revolução é, como regra geral, impossível. É o conjunto dessas alterações objetivas que constitui uma situação revolucionária. (LÊNNIN, 1979, p. 27 e 28.)

iii Reiteramos, mais uma vez, que isso significa dizer que não é em si transformadora, mas que pode contribuir para o processo de transformação, já que trabalha as consciências, a visão de mundo, a ideologia, potencializando, virtualmente, uma mudança de valores e atitudes perante si mesmo, os outros e o mundo.

${ }^{\text {iv }} \mathrm{O}$ pensamento científico embasado no materialismo histórico-dialético parte sim do real, dos fatos, mas, diferente do positivismo, questiona (daí ser essencialmente filosófico) se as coisas são como aparentam ser, buscando restabelecer a totalidade das relações sociais e de produção que trazem à tona o que está obliterado e eclipsado pelas aparências fenomênicas e factuais. Após retotalizar os nexos causais e as determinações reflexivas que medeiam e interdeterminam o(s) fenômeno(s), retorna ao fato, ao real, desvelando-o em toda sua complexidade, desnudando sua verdadeira essência, historicamente determinada. Como explica Saviani, a construção do pensamento histórico-científico-dialético do real se efetivaria da seguinte forma: "parte-se do empírico, passa-se pelo abstrato e chega-se ao concreto. Diferentemente, pois, da crença que caracteriza o empirismo, o positivismo, etc. (que confundem o concreto com o empírico) o concreto não é o ponto de partida, mas o ponto de chegada do conhecimento. E, no entanto, o concreto é também o ponto de partida. (Isto porque) o concreto-ponto de partida é o concreto real e o concreto-ponto de chegada é o concreto pensado, isto é, a apropriação pelo pensamento do real-concreto. Mais precisamente: o pensamento parte do empírico, mas este tem como suporte o real concreto. (...) Desse modo, o empírico e o abstrato são momentos do processo de conhecimento, isto é, do processo de apropriação do concreto no pensamento. Por outro lado, o processo de conhecimento em seu conjunto é um momento do processo concreto (o real-concreto). Processo, porque o concreto não é o dado (o empírico), mas uma totalidade articulada, construída e em construção. O concreto é, pois, histórico: ele se dá e se revela na e pela práxis". (SAVIANI, 2004, p. 4 e 5. O parênteses em itálico é nosso.) 